\title{
Influence of Test Cycles on Energy Consumption Test of Electric Vehicles
}

\author{
Yu $\mathrm{Liu}^{1,2 *}$, Kunqi $\mathrm{Ma}^{1,2}$, Hanzhengnan $\mathrm{Yu}^{1,2}$, Jingyuan $\mathrm{Li}^{1,2}$, Xiaopan $\mathrm{An}^{1,2}$ \\ ${ }^{1}$ China Automotive Technology and Research Center Co., Ltd., Tianjin, China \\ ${ }^{2}$ CATARC Automotive Test Center (Tianjin) Co., Ltd.
}

\begin{abstract}
In order to verify the necessity of the application of China Automotive Test Cycle which is constructed through actual driving data in china of more than 55 million kilometers in the energy consumption test of electric vehicles in China, this paper compares the characteristics of New European Test Cycle (NEDC), World-wide harmonized Light duty Test Cycle (WLTC) and China light-duty vehicle test cycle for passenger car(CLTC-P), and analyzes the differences of vehicle energy demand under different test cycles from theoretical and simulation point, simulation results show that the endurance mileage is longest and the energy recovery strategy is more effective under CLTC-P cycle. Finally, four types of vehicles are selected to carry out the endurance mileage test under these three test cycles. The test results are consistent with the simulation results. Therefore, in order to make the test results of electric vehicle energy consumption closer to the actual use of our country, CLTC-P should be selected to replace NEDC and WLTC cycle.
\end{abstract}

\section{Introduction}

In recent years, with the rapid development of China's electric vehicle market, the official endurance mileage of electric vehicles is getting larger and larger. However, the user survey shows that the endurance mileage of electric vehicles is one of the indicators of low satisfaction. One of the reasons is that there is a big difference between the actual endurance mileage and the official endurance mileage [1-2].

Although China has become the largest market of new energy vehicles in the world[3], the test standards of electric vehicles need to be further improved. As an important common basic technology in automobile test industry, test cycle is the basis of vehicle energy consumption and emission test method and standard. At the beginning of last century, China directly adopted NEDC for vehicle energy consumption and emission certification, which effectively promoted the development of vehicle energy conservation and emission reduction technology [4-7]. However, with the rapid growth of car ownership and the constant change of actual road in our country, the difference between NEDC test cycle and China Automotive Test Cycle is increasingly significant. Now NEDC cycle cannot represent the actual road situation in China, the relevant studies show that the NEDC test cycle is not suitable for evaluating the practical application effects of idle start-stop, braking energy recovery and other energy-saving technologies [7$8]$.

Based on the above background, in 2015, the Ministry of Industry and Information Technology, together with other four ministries and commissions, issued the task of
"China's New Energy Automobile Product Test and Development research" ("China Automotive Test Cycle"), and entrusted the China Automotive Test and Research Center (CATARC) to take the lead and organize the automobile industry to jointly complete it. After three years of research, "China Automotive Test Cycle" project team has established the largest working condition development database in the world, and developed 8 test cycles for light and heavy-duty vehicles. The passenger vehicle test cycle is CLTC-P.

In order to verify the necessity of application of China Automotive Test Cycle, this paper will analyze the influence of different test cycles on electric vehicle energy consumption from theoretical analysis, simulation and test.

\section{Characteristics of different test cycles}

The curves and the speed distribution of the three test cycles are shown in Figure 1 and Figure 2, and the main characteristics of the three test cycles are shown in Table 1.The main differences can be attributed to the following aspects:

Firstly, compared with NEDC cycle, WLTC and CLTC-P are transient test cycles, and all motion segments and idle segments are from actual road test data.

Secondly, the times of NEDC is only 1180 seconds, while WLTC and CLTC-P time are 1800 seconds, which is closer to the statistical results of users' travel time of one trip; apart from that the total mileage of these three working conditions is also different, the mileage of NEDC is $11 \mathrm{~km}$, which is only $1 / 2$ of $\operatorname{WLTC}(23.21 \mathrm{~km})$ and CLTC-P $(14.48 \mathrm{~km})$ is in the middle.

Corresponding author: liuyu2016@ catarc.ac.cn 
Third, the acceleration characteristics of these three cycles are different. The relative positive acceleration (RPA) reflects the driving intensity, CLTC-P is the most intense, NEDC is the most stable.

Fourth, the speed characteristics are different. According to the actual distribution of operating conditions in China, the vehicles mainly operate in low and medium speed phase, and the proportion of highspeed phase is relatively low.In terms of average speed, the average speed of WLTC $(46.42 \mathrm{~km} / \mathrm{h})$ is significantly higher than that of $\mathrm{NEDC}$, and the average speed of CLTC-P is the lowest; the average speed of CLTC-P is the closest to the weighted results of China's actual data. From the point of idle speed (less than $0.5 \mathrm{~km} / \mathrm{h}$ ), the idle speed ratio of CLTC-P is significantly higher than that of WLTC, and that of NEDC is slightly higher than that of CLTC-P. From the point of speed distribution, NEDC's speed interval distribution fluctuates greatly, which does not conform to the distribution of actual road, which is also the inherent defect of the steady-state condition; the proportion of WLTC working point in the range of less than $40 \mathrm{~km} / \mathrm{h}$ is significantly lower than that of CLTC-P, and the maximum speed is $131.31 \mathrm{~km} / \mathrm{h}, 5 \%$ of the operating points have exceeded the speed limit $(120 \mathrm{~km} / \mathrm{h})$ of China's vehicles.

In conclusion, compared with NEDC cycle, CLTC-P has the characteristics of frequent acceleration and deceleration and lower average speed; compared with WLTC cycle, CLTC-P has longer idle time and lower average speed.

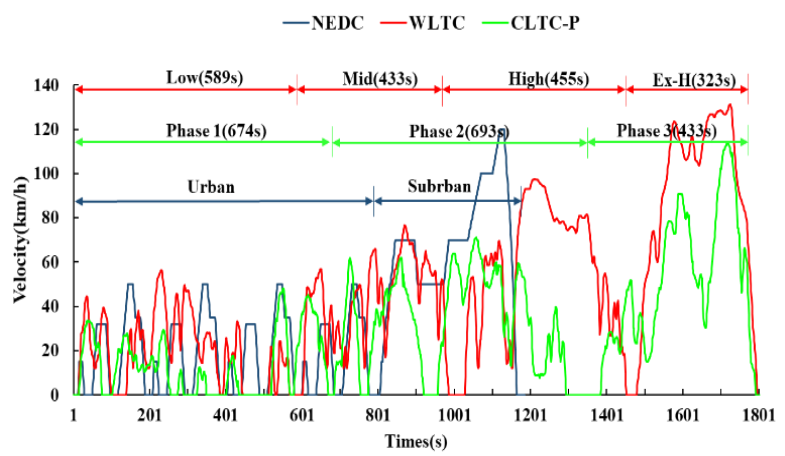

Fig. 1. NEDC、WLTC and CLTC-P test cycle.

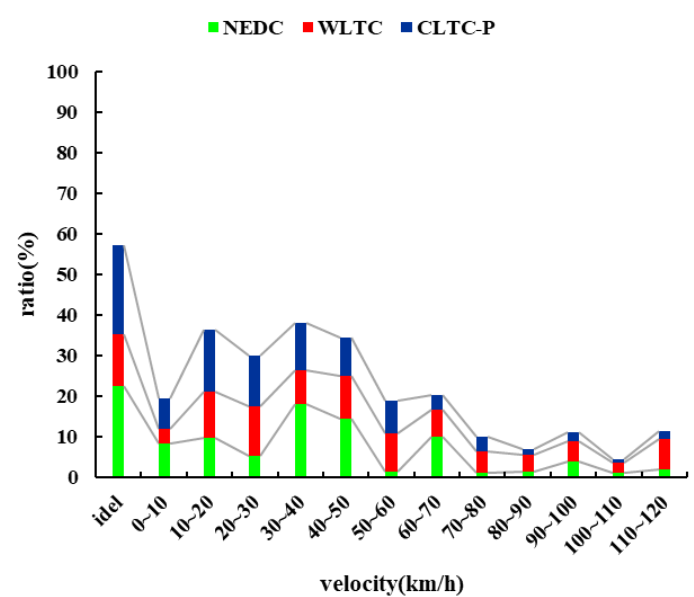

Table 1. Characteristics of NEDC, WLTC and CLTC-P.

\begin{tabular}{|c|c|c|c|c|}
\hline Test cycle & NEDC & WLTC & $\begin{array}{l}\text { CLTC- } \\
\text { P }\end{array}$ & $\begin{array}{l}\text { Weight } \\
\text { ed } \\
\text { results } \\
\text { of } \\
\text { China's } \\
\text { actual } \\
\text { data } \\
\end{array}$ \\
\hline $\begin{array}{l}\text { Times of test } \\
\text { cycle(s) }\end{array}$ & 1180 & 1800 & 1800 & I \\
\hline mileage $(\mathrm{km})$ & 11.03 & 23.21 & 14.48 & I \\
\hline Test phase & $\begin{array}{l}\text { Urban } \\
\text { and } \\
\text { suburb } \\
\text { an }\end{array}$ & $\begin{array}{c}\text { Low, } \\
\text { mediu } \\
\text { m, } \\
\text { high } \\
\text { and } \\
\text { Ultra } \\
\text { high } \\
\text { speed } \\
\text { phase }\end{array}$ & $\begin{array}{c}\text { Low, } \\
\text { mediu } \\
\text { m, } \\
\text { high } \\
\text { speed } \\
\text { phase }\end{array}$ & I \\
\hline $\begin{array}{c}\text { Maximum speed } \\
(\mathrm{km} / \mathrm{h})\end{array}$ & 120 & 131.3 & 114 & / \\
\hline $\begin{array}{l}\text { average speed } \\
(\mathrm{km} / \mathrm{h})\end{array}$ & 33.64 & 46.42 & 28.96 & 29.88 \\
\hline $\mathrm{RPA}(\mathrm{m} / \mathrm{s} 2)$ & 0.11 & 0.15 & 0.17 & I \\
\hline $\begin{array}{l}\text { Idle duration } \\
\text { ratio }(\%) \\
\end{array}$ & 22.62 & 12.67 & 23.7 & 22.05 \\
\hline $\begin{array}{l}\text { Maximum } \\
\text { acceleration } \\
\left(\mathrm{m} / \mathrm{s}^{\wedge} 2\right)\end{array}$ & 1.04 & 1.58 & 1.47 & I \\
\hline $\begin{array}{c}\text { Maximum } \\
\text { deceleration }(\mathrm{m} / \mathrm{s} \\
\wedge 2) \\
\end{array}$ & -1.39 & -1.49 & -1.47 & I \\
\hline $\begin{array}{c}\text { Average } \\
\text { acceleration } \\
\left(\mathrm{m} / \mathrm{s}^{\wedge} 2\right)\end{array}$ & 0.53 & 0.53 & 0.45 & / \\
\hline $\begin{array}{c}\text { Average } \\
\text { deceleration }(\mathrm{m} / \mathrm{s} \\
\wedge 2) \\
\end{array}$ & -0.7 & -0.58 & -0.49 & I \\
\hline
\end{tabular}

\section{Energy consumption under different test cycles}

\subsection{Comparison of energy consumption under different test cycles}

In order to verify the impact of test cycle on electric vehicle energy consumption, this chapter calculated the energy requirements of a certain light electric vehicle under NEDC, WLTC and CLTC-P test cycle, and the difference is analysed from the point of vehicle dynamics.

Figure 3 is the battery energy consumption of this vehicle under different test cycle. It can be seen from the figure that the battery energy consumption of CLTC-P is the lowest, followed by NEDC, and the energy consumption under WLTC is highest.

Fig. 2. Speed distribution of different cycles 


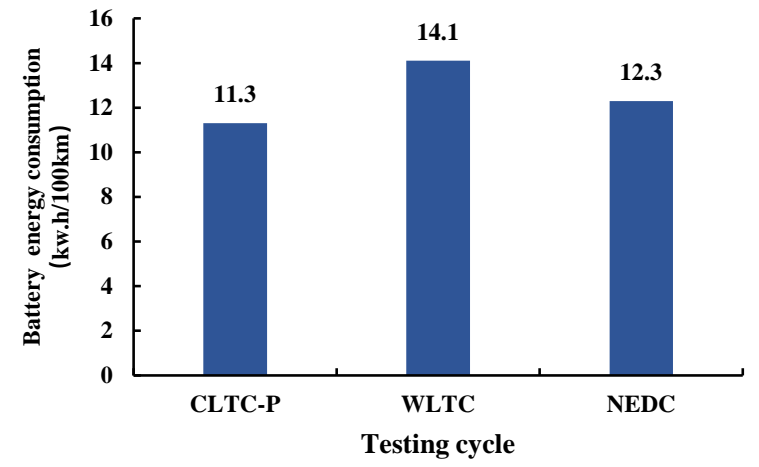

Fig. 3. Energy consumption under different test cycle.

Formula 1 is the vehicle dynamics equation[9]:

$$
\frac{T_{t q} i_{g} i_{0} \eta}{r}=m g f \cos \alpha+\frac{C_{D} A u_{a}^{2}}{21.15}+m g \sin \alpha+
$$

Where: $T_{t q}$ is required torque of motor, $i_{g}$ is transmission ratio, $i_{0}$ is final driver ratio, $\eta$ is motor efficiency, $r$ is rolling radius, $m$ is gross mass, $f$ is coefficient of rolling resistance, $C_{D}$ is coefficient of air resistance, $A$ is frontal area, $\alpha$ is road slope.

According to Formula 1, when the vehicle type and test conditions are determined, the energy consumption of the battery is directly proportional to the square of vehicle speed and acceleration, and the speed has a greater impact on the energy consumption of the battery under different testing cycle. Therefore, the high energy consumption of WLTC is mainly due to its higher average speed.

\subsection{Simulation of endurance mileage under different test cycles}

Braking energy recovery technology is one of the important means of energy saving. All electric vehicles will carry this technology. At present, there is no unified standard for the evaluation method of braking energy recovery in China. In this paper, the contribution degree of endurance mileage is introduced to evaluate the braking energy recovery effect under the three test cycles.

The calculation formula of endurance mileage contribution degree is as follows[10]:

$$
\delta_{S}=\frac{S_{1}-S_{2}}{S_{2}} \times 100 \%
$$

Where: $\delta_{S}$ is the endurance mileage contribution; $S_{1}$ is the endurance mileage with braking energy recovery under a given battery energy under a cycle condition; $S_{2}$ is the endurance mileage without braking energy recovery under the same testing conditions.

Figure 4 shows the simulation results of the endurance mileage of the electric vehicle under three test cycles, other simulation parameters remain unchanged during the switch of testing cycle. It can be seen from the figure that, whether the braking energy recovery strategy is activated or not, the endurance mileage under CLTC-P is the longest, followed by NEDC mode, and the endurance mileage under WLTC is the shortest.

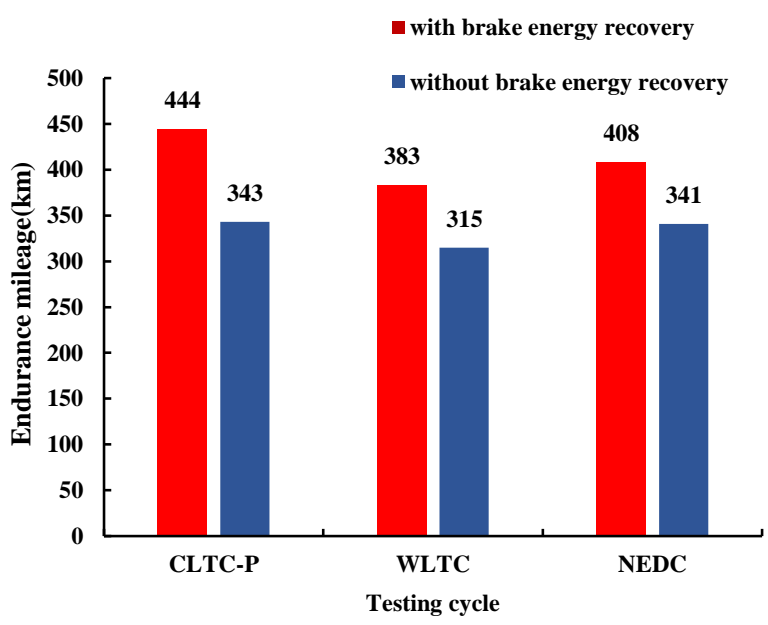

Fig. 4. Comparison of endurance mileage with and without brake energy recovery strategy.

By substituting the data in Figure 4 into formula (2), the contribution of braking energy recovery to endurance mileage is $19.65 \%, 21.59 \%$ and $29.45 \%$ respectively under NEDC, WLTC and CLTC-P cycle. That is to say, the effect of braking energy recovery strategy is directly proportional to the braking mileage, braking frequency and the load of braking force.

\section{Test comparison}

In order to verify the correctness of the above simulation results, four electric vehicles are selected to test the endurance mileage under the three different conditions. The test was carried out by conventional driving cycle method, the test basis is GB18386-2017.The test results are shown in Figure 5.

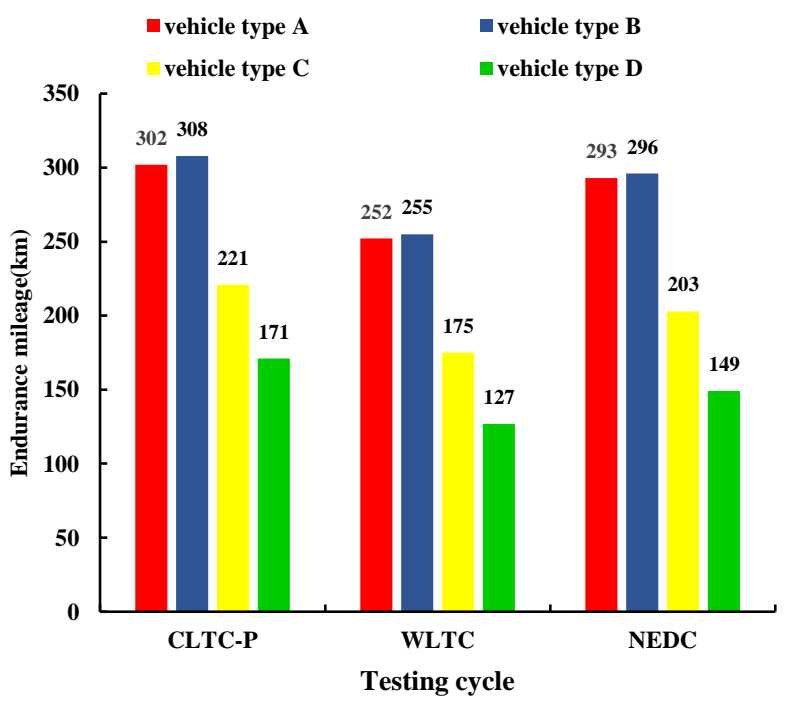

Fig. 5.Comparison of endurance mileage under different test cycles 
It can be seen from the Figure 5 that the endurance mileage of these four vehicles under the three test cycle are consistent, that is, the endurance mileage under WLTC is the shortest, the endurance mileage under CLTC-P is the longest and NEDC is slightly shorter than CLTC-P. In other words, the real energy consumption of the three working conditions from large to small is WLTC > NEDC > CLTC-P, this is consistent with the simulation results.

\section{Conclusions}

Compared with WLTC and NEDC cycle, CLTC-P has the characteristics of low average speed, high idle proportion and frequent acceleration and deceleration. The test results show that CLTC-P has the lowest energy consumption, NEDC is slightly higher than CLTC-P and WLTC is the highest, which is consistent with the theoretical and simulation results. Therefore, the choice of test cycle has an important impact on the energy consumption test results of electric vehicles. Only the actual test cycle can guide the technology to obtain the test results in accordance with the actual conditions. Therefore, in order to make the test results of electric vehicle energy consumption closer to the actual use of our country, CLTC-P should be selected to replace NEDC and WLTC cycle.

\section{References}

1. Xinkai, $\mathrm{Wu}$, et al. "Electric vehicles' energy consumption measurement and estimation." Transportation Research, Part D. 2015.

2. Huo, Y, et al. "Comparison and Study of NEW Energy Consumption Test and Evaluation Procedures." Digest(Chinese),2020(8):11-14.

3. Friedlingstein, $\mathrm{P}$, et al. "Persistent growth of $\mathrm{CO} 2$ emissions and implications for reaching climate targets." Nature Geoscience. 2014(7):709-715.

4. Wang, Z, et al "New Fuel Consumption Standards for Chinese Passenger Vehicles and their Effects on Reductions of Oil Use and $\mathrm{CO} 2$ Emissions of the Chinese Passenger Vehicle Fleet." Energy Policy 38(9):5242-5250.

5. Tutuianu, M, et al."Development of the World-wide harmonized Light duty Test Cycle (WLTC) and a possible pathway for its introduction in the European legislation,"Transp. Res. Part D Transp. Environ. 40:61-75, 2015.

6. Liang, Li, et al."Model predictive control-based efficient energy recovery control strategy for regenerative braking system of hybrid electric bus." Energy Conversion and Management. 111:299$314,2016$.

7. Mock, P., Kuhlwei, J., Tietge, U., Franco, V. et al., "The WLTP: How a New Test Procedure for Cars will Affect Fuel Consumption Values in the EU,"
International Council on Clean Transportation 9:3547, 2014.

8. United Nations, "Addendum 15: Global technical regulation No. 15 - Worldwide harmonized Light vehicles Test Procedure," Glob. Regist. ECE/TRANS/:1-234, 2014.

9. Huo, H., Yao, Z., He, K., and Yu, X., "Fuel Consumption Rates of Passenger Cars in China: Labels Versus Real-World," Energy Policy 39(11):7130-7135, 2011, doi: 10.1016/j.enpol.2011.08.031.

10. Weiss, M., Bonnel, P., Hummel, R., Provenza, A., and Manfredi, U., "On-road emissions of light-duty vehicles in Europe," Environ. Sci. Technol. 45(19):8575-8581, 2011, doi:10.1021/es2008424. 